\title{
Evaluation of PAX8 expression promotes the proliferation of stomach Cancer cells
}

\author{
Liang-Yu Bie', Ning Li', Wen-Ying Deng ${ }^{1}$, Xiao-Yu Lu², Ping Guo ${ }^{3}$ and Su-Xia Luo * (D)
}

\begin{abstract}
Background: PAX8 was not only a mitotic factor, but identified as a transcription factor i olva in the prognosis of human tumor patients. Elucidating the function of PAX8 on the pathology of stomash c. rer was meaningful.

Results: PAX8 was found to be upregulated in primary stomach cancer tissue and TCGA s,omach cancer dataset. Interestingly, SOX13 and PAX8 showed consistent expression patterns, and the mbined high PAX8 and SOX18 expression induced a worse prognosis of stomach cancer patients. SCA was fur, ner identified as a transcription factor of PAX8, and further affect Aurora B and Cyclin B1 expr. ior cell cycle related factors of the downstream of PAX8, including. Furthermore, PAX 8 depletion inducted $G$ thase arrest and the decrease of EdU incorporation, cell viability and colony formation can be rescued soX13) vverexpression.

Conclusions: SOX13 participated in the elevated expression of PAX8, which,promote the proliferation of stomach cancer cells. Therefore, SOX13 mediated PAX8 expression was recognizedyas a tumor-promoting role in stomach cancer.
\end{abstract}

Keywords: PAX8, Expression, Proliferation, Stomach

\section{Background}

Stomach cancer was one of the high risk cancel related deaths worldwidely, with the charact tic of rapid pathological progress and $10 \mathrm{w}$ screenin $\%$ efficiency [1, 2]. Recently, stomac cancel patients undergoing traditional treatment, ludieg surgery, chemotherapy and other the nies, showed high recurrence, causing widespread on $/ 3-5]$. However, drugs targeting to cel olifer ation regulator, which were developed for $s$ mnression the tumor malignant proliferation, ha, shown a strong anti-cancer effect and sig antly $r_{0}$ cuced the risk of death and recurrence oil pat ts, binging new light to the treatment of stomach cy,ncer [6, 7]. Therefore, the study of the If ula mechanism of the malignant prolifera $^{+} n$ of mach cancer cells is of great significance rr e sloring potential therapeutic targets and the deve mincm of drugs for stomach cancer [8].

* Correspondence: yanqi26825300@163.com

${ }^{1}$ Department of Oncology, Affiliated Cancer Hospital of Zhengzhou University Henan Cancer Hospital, Zhengzhou, NO. 127, Dongming Road, Jinshui District, Zhengzhou 450008, Henan, China

Full list of author information is available at the end of the article
Transcription factor PAX8, an important regulator of embryo development [9], was associated with abnormal kidney development in male PAX8 knockdown mice and endometrial dysfunction in female PAX8 knockout mice [10]. Notably, PAX8 was highly expressed in human malignancies, and significantly enhanced the proliferation of tumor cells via regulating the expression of cell cycle regulator, such as Aurora B and Cyclin B1 [11, 12]. Upregulation of PAX8 in endometrial and ovarian cancer tissues $[13,14]$ was accompanied with a higher risk of death and high recurrence in patients [15]. However, the clinical significance of PAX8 and its function on proliferation of human stomach cancer was confusing.

In addition to maintain the stemness of stem cell by involved in regulating the Wnt / $\beta$-catenin signaling pathway, SOX13 has also been reported to be abnormally expressed in cancer tissues containing poorly differentiated cells $[16,17]$. SOX13 containing the HMG-box domain can provide a platform for recruiting other transcriptional molecules to regulate the transcription of target genes by combining HMG-box homologous sequences in the promoter region of target genes $[18,19]$. SOX13 has been reported as a molecular marker for the diagnosis of potential malignant tumors, 
and its high expression in malignant tumors usually resulted with a poor survival prognosis for patients [20]. However, the expression pattern and molecular function of SOX13 in stomach cancer was rarely studied.

In our study, the clinical significance and molecular function of SOX13 and PAX8 in stomach cancer were discussed, and the proliferation of stomach cancer cells promoted by SOX13-regulated PAX8 expression was expounded, providing a new insight into the mechanism of malignant proliferation of stomach cancer cells.

\section{Result}

\section{PAX8 and SOX13 are upregulated in stomach cancer}

The TCGA stomach cancer database was first used to retrieve the expression patterns of all the PAX family transcription factors, and the expression of PAX8 was found to be significantly up-regulated in stomach cancer tissues compared to normal tissues (Fig. 1a). Although the cancer-promoting role of PAX8 in most types of tumors has been widely reported, the clinical significance and molecular function of PAX8 in stomach cancer remain puzzling. In order to verify whether PAX8 is related to the pathological progression of stomach cancer, the expression pattern of PAX8 in stomach cancer tissues with different pathological progression was further explored. Interestingly, in four stomach cancer tis oues with different stages, the expression of PAX8 sho 1 an increasing trend by the pathological stages (Fig. $\mathrm{b}$ ).

To further explain the up-regulated PAX8 mRNA in stomach cancer, we were inte ted in the fact that HMG-box transcripti, n elements were found to be widely present in the romoten region of PAX8, suggesting that the increased ressi on PAX8

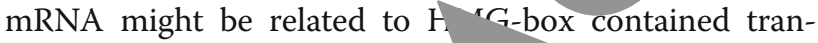
scription factors. By analyzing the aA stomach cancer database, we found the expression of HMG-box domain contained So 13 als 0 up-regulated, and the SOX13 expressio was sitively correlated with the expression patter ${ }_{1}$ PAX8 $y=0.6567, p<0.001$ ) (Fig. 1c).

Furthermore, q $\mathrm{PCR}$ assay revealed that SOX13 showed onsistent $\mathrm{u}_{2}$-regulated expression patterns as similar P.X8 in 36 pairs of stomach cancer tissues $(\mathrm{Fi}-1 \mathrm{~d}$, e adition, spearman correlation analysis of e m NNA lever of PAX8 and SOX13 in stomach tumor $t_{1}$. es suggested a strong positive correlation $(\mathrm{r}=$ 0.65 $p<0.001$ ), consistent with TCGA-based results (Fig. If).

To explore the differences of PAX8 and SOX13 expression pattern in different stomach cancer cell lines, SOX13 was found to significantly up-regulated in stomach cancer cell lines as the expression pattern of PAX8, especially in MGC803 and AGS cell lines, by comparing PAX8 and SOX13 expressed in 4 stomach cancer cell lines with GES1 cells (Fig. 1g, h). However, it was noted that the mRNA and protein level of PAX8 was overexpressed in cell lines where SOX13 mRNA and protein were also significantly up-regulated, suggesting the positive correlation of SOX13 and PAX8 (Fig. 1g, h).

\section{Upregulated SOX13 and PAX8 was associated with "orse prognosis of stomach cancer patients \\ Immuno-histochemical staining of stomach can spec-} imens was performed to explore the distributl of PAX8 and SOX13 in stomach cancer the es. The staining section indicated that PAX8 we main dis ributed in the nucleus, as the stain resu $t$ of SOX1, (Fig. 2a). Furthermore, 36 clinical tissues $\mathrm{w}$ classilied according to the staining levels of $\mathrm{PA}$ ana 13 , and the results indicated that the proten of, SOX13 and PAX8 expressed in tissues se ignific ntly different ( $\chi^{2}$ test, $p=0.0361)$. In brief, $47.2 \quad(17 / 36)$ of stomach cancer patients was ac $\mathrm{Om}_{\text {, }}$ nied with SOX13 and PAX8 overexpression, $w h .22 \%(8 / 36)$ of patients showed a lower expressio f PAX8 and SOX13 (Fig. 2b), indicating th ababilicy that PAX8 shared the same expression patterr as SOX13 in stomach cancer.

Furthermere, weather the level of SOX13 and PAX8 in Sto ch cancer was correlated with the survival of patients vas explored, in order to clarify the clinical significe of SOX13 and PAX8. By comparing the survival $\mathrm{Cu}_{i}$ ves, it was found that not patients with high level of PAX8 significantly resulted with worse survival compared to patients with low PAX8 expression, but also SOX13 did (Fig. 2c, d). In stomach cancer patients with the same expression patterns of SOX13 and PAX8, combined low SOX13 and PAX8 expression was found to result with a better overall survival rate, but not upregulated SOX13 and PAX8 (Fig. 2e). These results suggest the clinical significance of SOX13 and PAX8 in stomach tumors, which can be used as potential biological indicators for the survival of patients with stomach cancer.

\section{SOX13 regulates the transcription of PAX8 in stomach cancer}

In order to verify that the up-regulated expression of PAX8 in stomach cancer is related to SOX13, we verified whether SOX13 can regulate PAX8 expression in stomach cancer cell lines. It was first found that different amounts of SOX13 overexpression could cause the associated increase of PAX8 mRNA and protein expression level in AGS and MGC803 cells (Fig. 3 a, b). Moreover, silencing SOX13 can downregulate PAX8 mRNA and protein expressed in AGS and MGC803 cell lines, while SOX13 overexpression can rescue the down-regulation of PAX8 to some extent caused by SOX13 knockdown. However, even overexpressed SOX13 mutants (SOX13 ins6), in which 


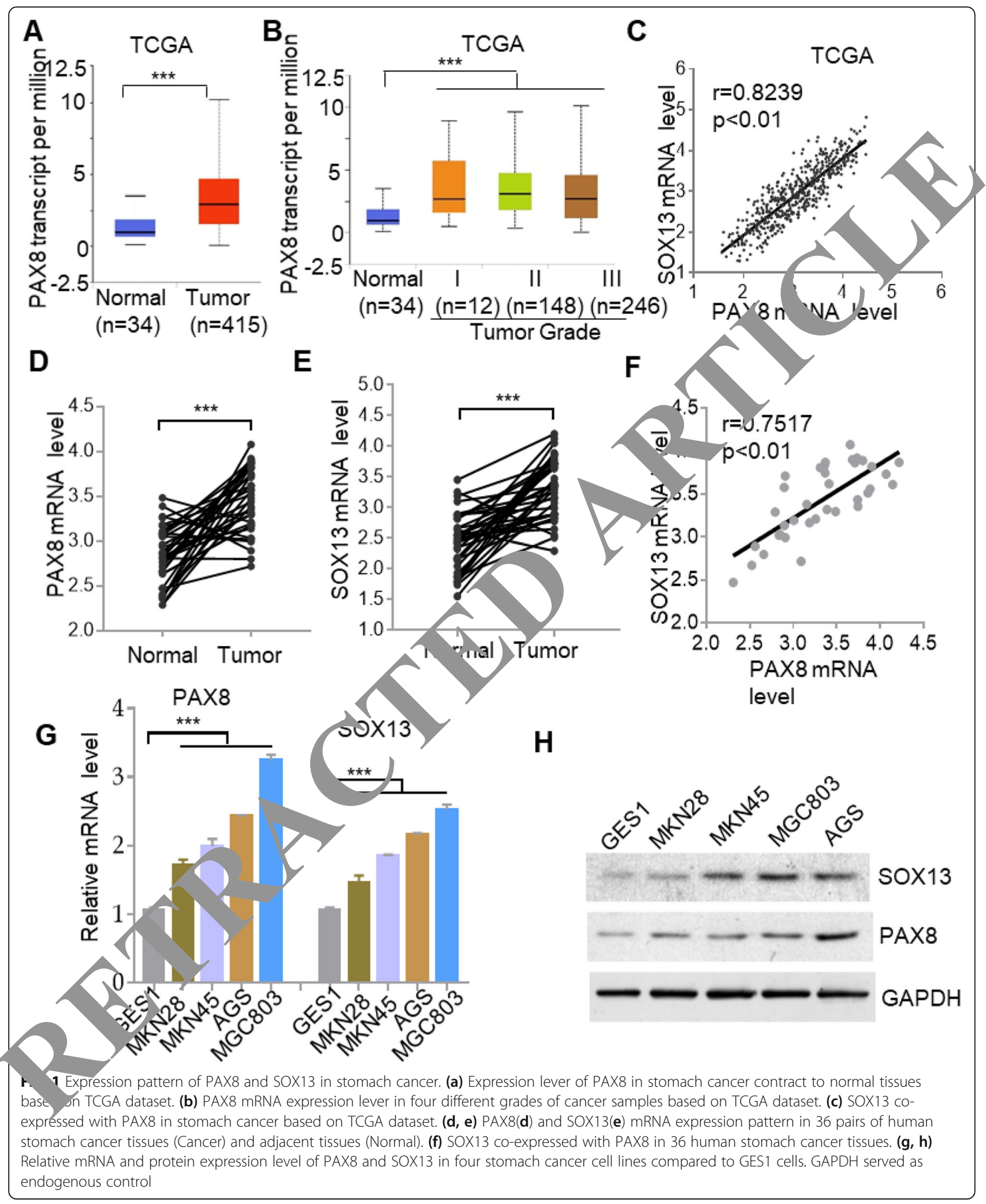

six amino acids were inserted into the HMG-box of SOX13 to deprive its ability to bind with the HMGbox DNA sequence, cannot reverse the decline in
PAX8 expression (Fig. 3c, d). These results confirmed that SOX13 was one of the factors regulating PAX8 expression in stomach cancer. 


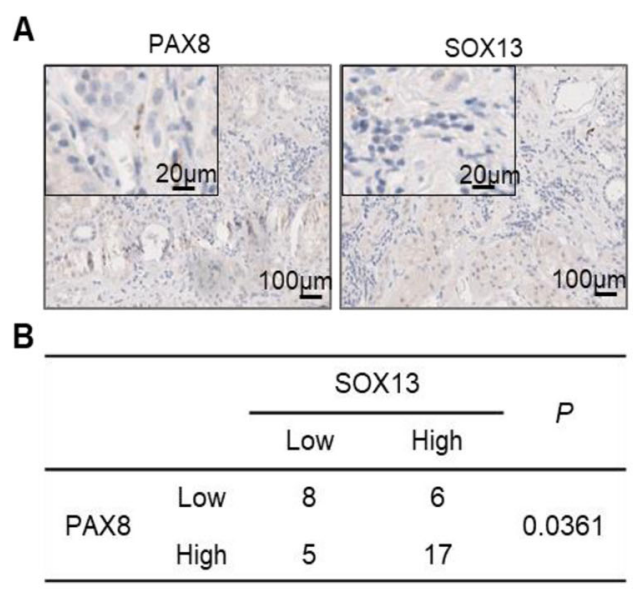

C
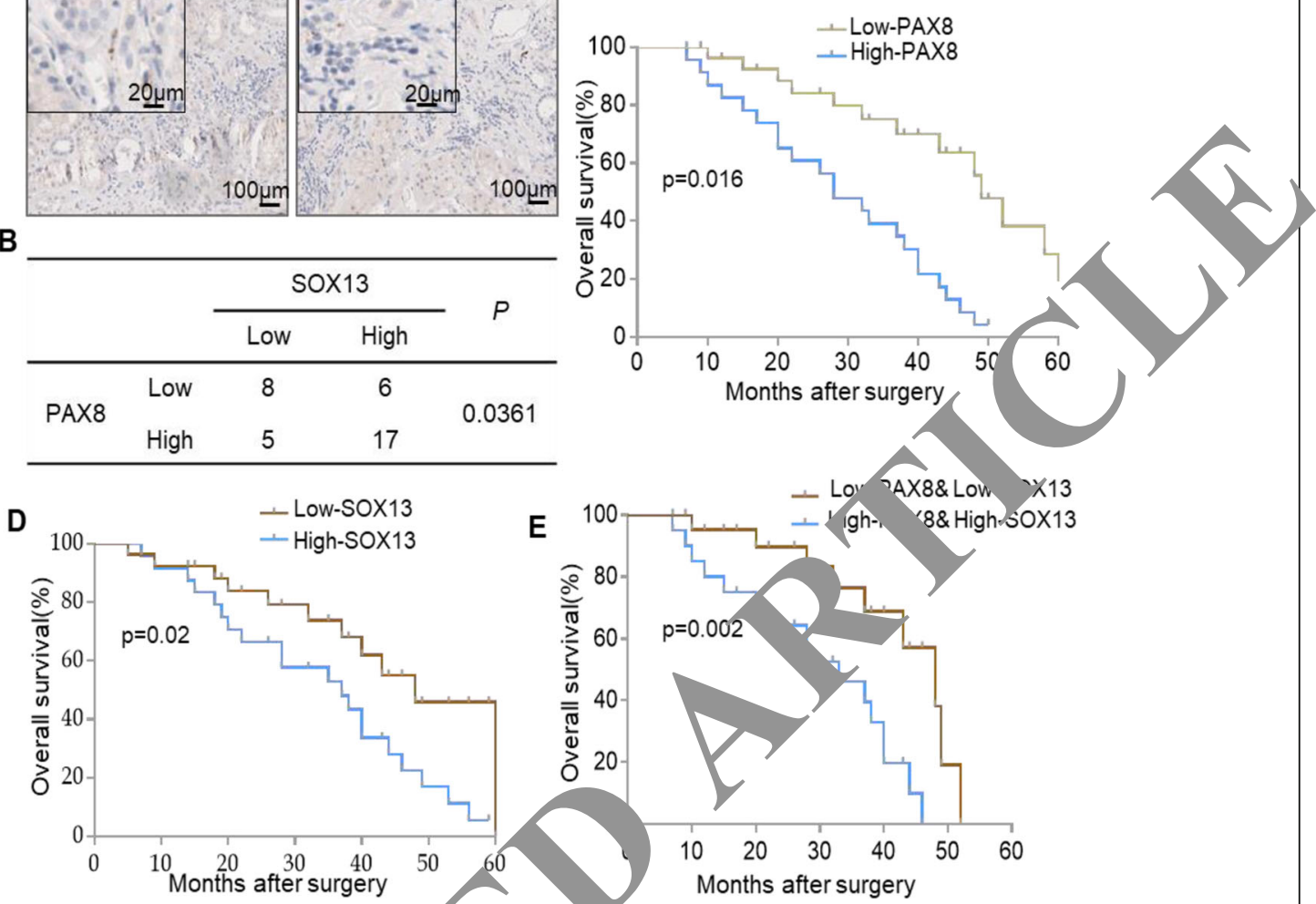

Fig. 2 Combined PAX8 and SOX13 expression may predict th analysis of PAX8 and SOX13 expression in 36 stomach can ursar. s. (b) Correlation of PAX8 and SOX13 was statistically analyzed. (c, d) Overall survival of patients with stomach cancer was calculated ing Kaplar eier analysis according to low and high PAX8(c) or SOX13(d) staining. The $P$ values were calculated by log-rank test. (e) OV rall. ival of patients with stomach cancer was calculated according to combined PAX8 and SOX13 staining level

Since SOX13 has been proved thegul te the expression of PAX8 in stomacl ancer, luciferase assay was further used to explor combination of SOX13 with the prom region of PAX8, in order to verify that SOY w a transcription factor of PAX8. Although SOX overexpression was found to significantly ir ase the xpression of reporter genes containing the PA promoter, SOX13 lost its ability to prom te reporter gene expression, when the PAX8 promou $r$ ion was reduced by more than $600 \mathrm{bp}$ on the ${ }^{-} r$ te $n a$ / (Fig. 3e), suggesting that SOX13 may ind with the $-300 \sim-600 \mathrm{bp}$ regions of the PAX8 $\mathrm{p}$ noum to regulate PAX8 expression. Furthermore, Chl $R C R$ assay showed that SOX13 could significantly enrich the $-300 \sim-600 \mathrm{bp}$ region of PAX8 promoter, confirming the interaction between SOX13 and PAX8 promoter (Fig. 3f).

Previous studies have shown that Aurora B and Cyclin $\mathrm{B} 1$, as mitotic regulators, can be regulated by PAX8 and thus affect the progression of tumor cell cycle, which promoted us to speculate whether SOX13-regulated PAX8 expression can affect the expression of Aurora B and Cyclin B1 in stomach cancer. PAX8 silencing can significantly cause the silencing of Aurora B and Cyclin B1, the expression of Aurora B and Cyclin B1 were recovered, when PAX8 was expressed in AGS and MGC803 cells, confirming that PAX8 can regulate the expression of Aurora B and Cyclin B1 in stomach cancer (Fig. 3g). Moreover, wild type SOX13 expression also restores the mRNA level of Aurora B and Cyclin B1, in parallel with the upregulated expression of PAX8 to a certain extent (Fig. 3g), suggesting the notion that SOX13-regulated PAX8 expression affects the expression pattern of Aurora B and Cyclin B1 in stomach cancer.

\section{SOX13-mediated PAX8 expression promotes cellular proliferation in stomach cancer}

In view of the positive effect of SOX13-regulated PAX8 expression on cellular Aurora B and Cyclin B1 expression, SOX13-regulated PAX8 expression function on cell cycle was detected. And flow cytometry assay showed that PAX8 knockdown induced G1-phase arrest in AGS and MGC803 cell lines, which could be rescued by 
A

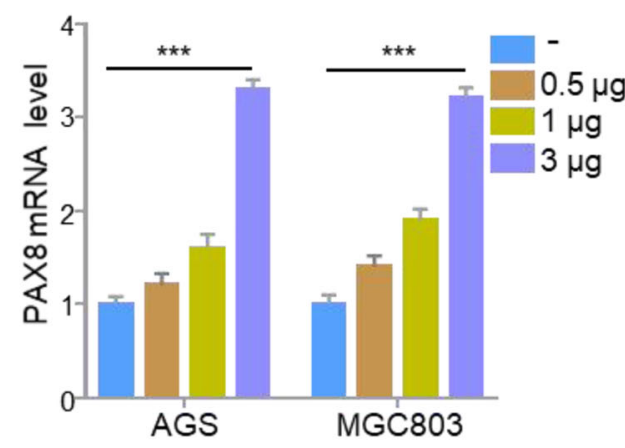

C
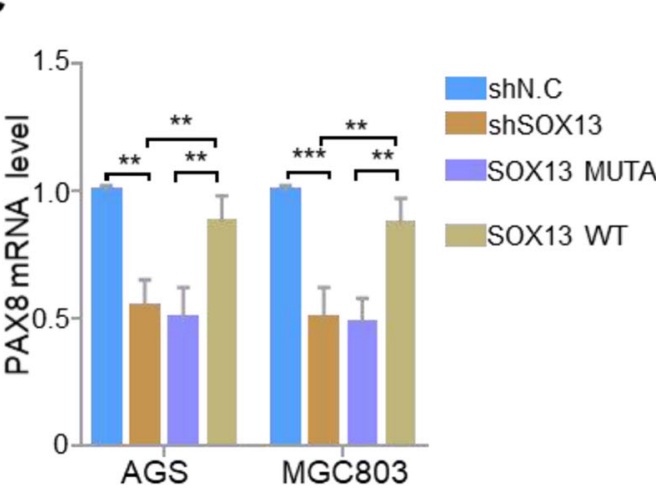

B

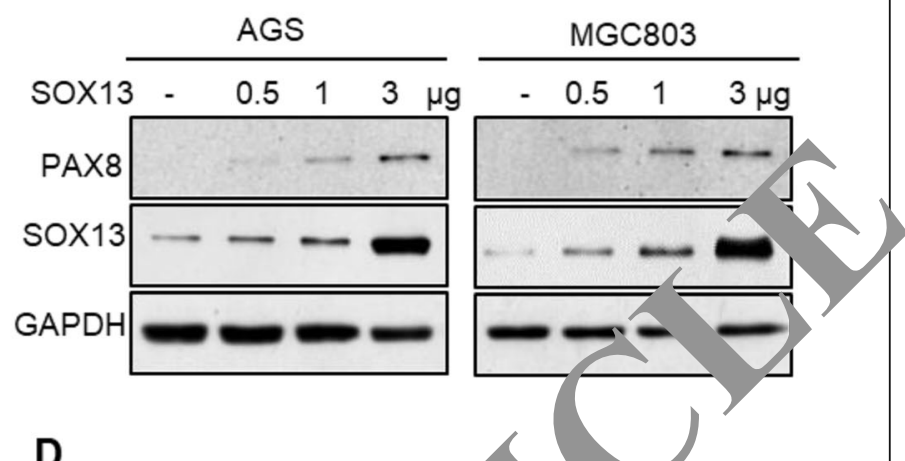

D

E
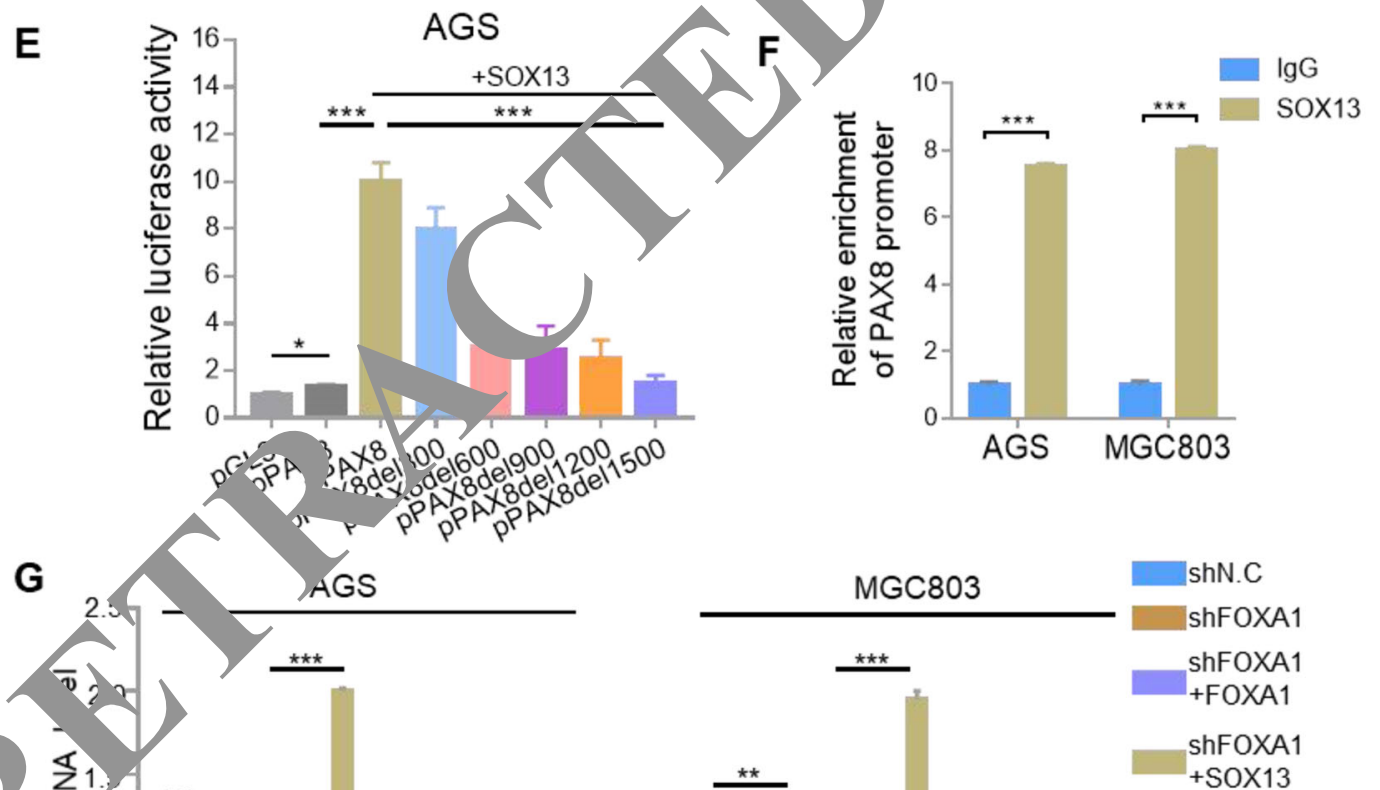

变

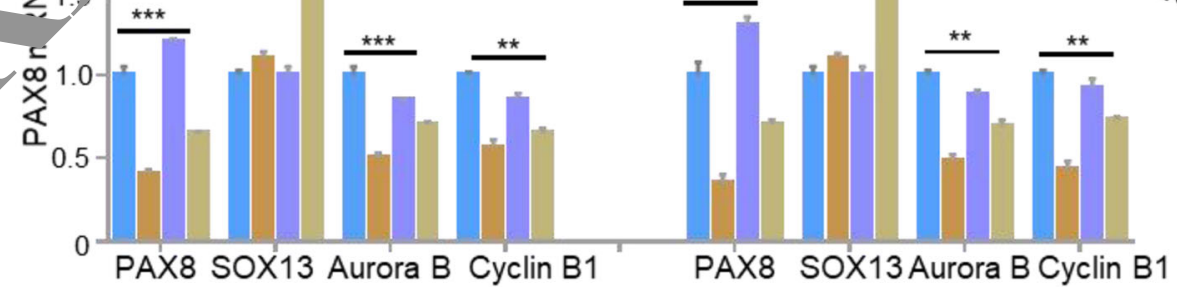

Fig. 3 (See legend on next page.) 
(See figure on previous page.)

Fig. 3 PAX8 expression pattern can be regulated by SOX13 in stomach cancer. (a, b) Relative mRNA and protein expression of PAX8 in SOX13 overexpressed AGS and MGC803cell lines. (c, d) SOX13 can rescue mRNA and protein expression level of PAX8 in AGS and MGC803 cell lines. (e) PAX8 promoter deletions fused to the luciferase reporter gene were transfected with SOX13 in AGS cells. (f) ChIP assay was used to examine the interaction of PAX8 promoter with SOX13 in AGS and MGC803 cell lines. (g) SOX13 mediated PAX8 targeted genes expression in AGS and MGC803 cell lines

SOX13 overexpression (Fig. 4 a, b). What's more, the overexpression of SOX13 can significantly increase the decline of EdU positive cells induced by PAX8 knockdown, no matter in AGS cells or in MGC803 cells, indicating that SOX13-mediated PAX8 expression can promote the progression of cell cycle in stomach cancer (Fig. 4 c, d).

Next, whether PAX8 function on the cellular viability in stomach cancer was detected, which was one of the indicators for malignant proliferation of tumor cells. The results showed that PAX8 knockdown could directly weaken the viability of stomach cancer cells, while the up-regulation of PAX8 expression induced by SOX13 overexpression restored the cell viability (Fig. 4 e). Consistently, SOX13 overexpression can significantly increase the PAX8 silencing-induced decrease of clone formation in both AGS cells and MGC803 cells, indicating that SOX13-mediated PAX8 can promote the tumorigenicity of stomach cancer cells (Fig. $4 \mathrm{f} / \mathrm{g}$ ). Therefore, the expression of PAX8 regulated by $x$ ? can promote the progress of stomach cancer Cal C) showing the capbilty to promote tumorigen; of stom. ach cancer cells.

\section{Discussion}

Exploring for the feasible targets to hibit malignant tumor cell proliferation has be me one of the direction of development of new cures for $a_{-}, r$, including cancers of the stomach, ex for the traditional treatment for stomach cancer 1,2 Therefore, it is still a hot topic in the resea $\mathrm{ch}$ on omach cancer to find the molecular and sig, transdu, - Ion pathways related to proliferation regulatio $[23,24]$. Studies have shown that up-regul red express, on of PAX8 in malignant tumors, includir. $d$ osti ve and urinary tumors, has also been she to a biomarker for the diagnosis of ovarian rd k iney c ncer, and has been the focus of researchers [2 20]. necently, the effect of PAX8 has been indicated to su ort the clearance of tumor cells and be the prediction of survival time in tumor patients [12]. The proliferation of rat thyroid cells can be significantly inhibited by silencing the expression of PAX8, revealing the importance of PAX8 in regulating the proliferation of thyroid cells [27]. In addition, the high expression of PAX8 has been shown to regulate the lifespan of tumor cells by activating telomerase activity in gastrointestinal and nervous system tumors [28]. Although these studies have revealed PAX8 function on the cell cycle gression in different types of tumors, the effect of PA. the cellular proliferation in stomach can has nt been reported.

In this study, we identified t at PAX8), vas highly expressed in stomach cancer an that the worse prognosis was found in stomact. nce.clents with high PAX8 expression. Furth rmore, $4 \times 8$ had the ability to regulate the expression Auror, $\mathrm{B}$ and Cyclin B1 in stomach cancer cells, whic vrther revealed the capability of PAX8 to stec the cellalar tumorigenicity in stomach cancer by of of the progression of stomach cancer cell cycle. $\eta$ addition, the downregulation of PAX8 car sed arrest the cell cycle in stomach cancer and reduce the cumorigenesis of stomach cancer cells, indicating that PAX8 played a carcinogenic role in the Pa. logical development of stomach cancer. Whatever, these esults suggest the potential value of PAX8-related naing pathways in the diagnosis and treatment of stomach cancer.

Members of the SOX family expressed in embryonic tissue or stem cells have the ability to maintain cellular stemness and regulate differentiation [29, 30]. In recent years, HOM-box domain contained SOX family transcription factors have been found to be abnormally expressed in tumor cells and involved in regulating tumor cell growth, such as SOX10 and SOX12 [31]. SOX10 can be used as a serum biomarker to increase the efficacy of GPM6B and COL9A3 in the diagnosis of basal breast cancer and the prognosis of patients, which was mainly related to its function on the proliferation of breast tumor cell [31]. Similarly, the upregulation of SOX12 was aslo indentified as a biomarker of poor prognosis in colon cancer patients [32]. In addition, the proliferation of colon cancer cells was significantly inhibited by knocking down SOX12 expression [33], suggesting the significance of SOX family in regulating the proliferation of cancer cells. In this study, the up-regulated expression of SOX13 was found to be positively correlated with the expression of PAX8 in stomach cancer tissues. Interestingly, SOX13 was confirmed as a transcription factor of PAX8 to regulate the expression of PAX8 and its downstream cycle-related Aurora B and Cyclin B1 in stomach cancer cells, which promoted the progression of stomach cancer cell cycle and enhanced the tumorigenicity of stomach cancer cells, suggesting that SOX13, as one of the tumor cell cycle regulators, was oncogene in stomach cancer. 


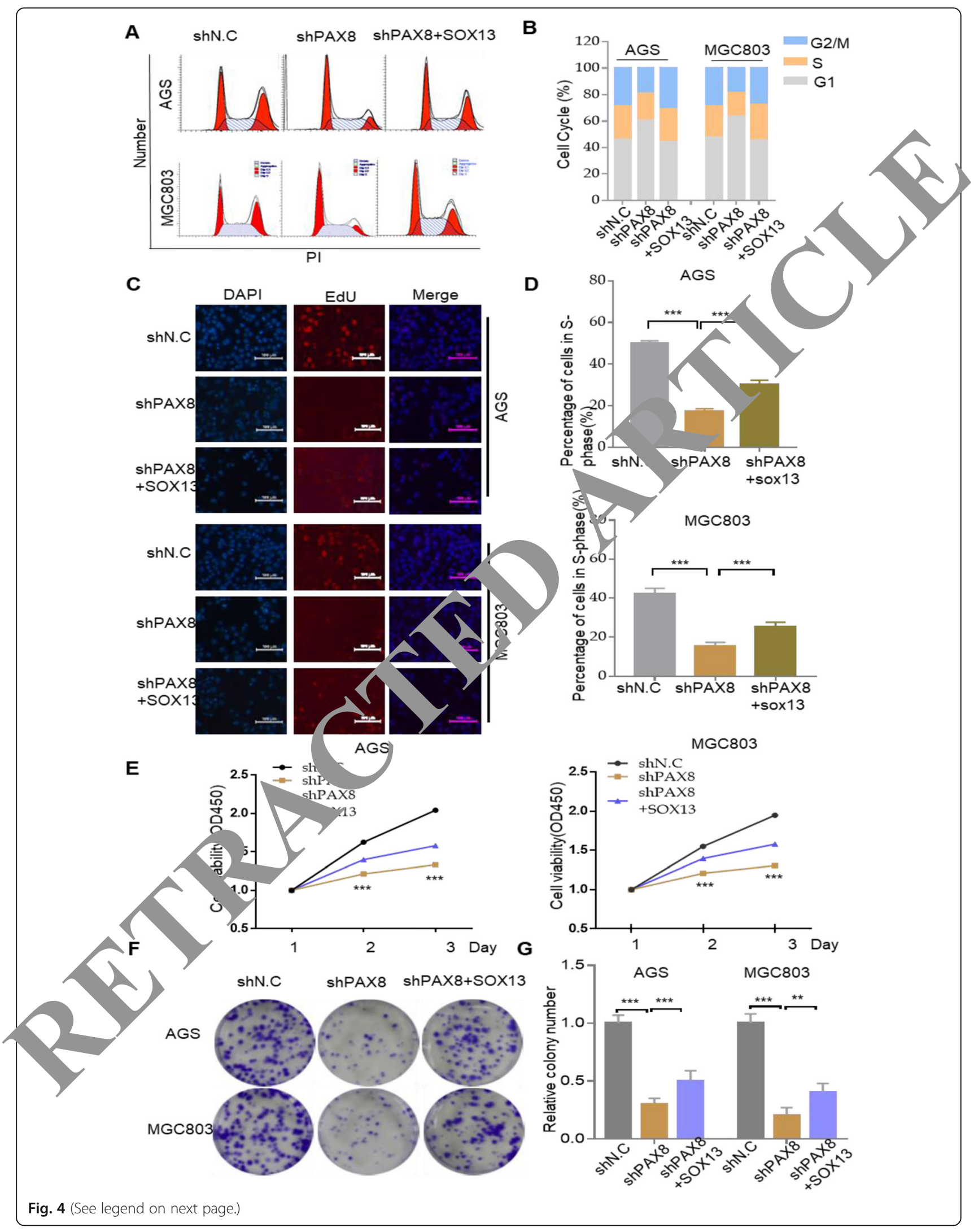


(See figure on previous page.)

Fig. 4 SOX13 dependent PAX8 expression promotes cell proliferation in stomach cancer. (a, b) Flow cytometry analysis of cell cycle distribution in PAX8 silenced AGS and MGC803 cell lines and controls. (c, d) EdU incorporation assay showed the percentage of in S-phase in PAX8 silenced AGS and MGC803cells. (e) CCK8 assay showed cells viability in PAX8 silenced AGS and MGC803 cells. (f, $\mathbf{g})$ The clone formation assay in PAX8 silenced AGS and MGC803 cells and controls

\section{Conclusions}

In conclusion, PAX8 were confirmed to be overexpressed in primary stomach cancer, and SOX13 mediated PAX8 expression promoted the proliferation and tumorigenesis of stomach cancer cells. Furthermore, upregulated SXO13 and PAX8 showed an unfavorable factor for the clinical prognosis of patients. However, for exploring the mechanism of cancer cellular proliferation, it will be significant to further explore the network of PAX8 in stomach cancer.

\section{Methods}

\section{Cell lines}

Stomach cancer cell lines (MKN45, MKN28, MGC803, AGS) and GES1 cell lines were purchased from American Type Culture Collection (ATCC, USA). MKN45, MKN28, MGC803 and AGS were cultured in RPM1636 Medium containing 10\% fetal bovine serum (Gibco) and GES1 in Dulbecco's Modified Eagle Medium (DMEM) containing 15\% fetal bovine serum (Gibco).

\section{Human tissue specimens}

The stomach cancer tissues and para-canco tissues of 36 cases were collected from stomach cancer p. nts in Henan Cancer Hospital. All patients gned the int $s$ rmed consent and did not receive chemot rapy or radiotherapy before surgery. Some of the tissu as uced for gene expression analysis, while the i was fixed with formalin for immune-histochemical a nar/ All patients were collected and kept corr te midical records. The experiment was sup tec hy the institute's ethics committee.

\section{Immunohistochem}

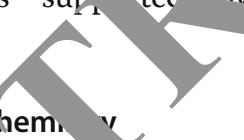

Formalin solution in nobilized tissues were dewaxed in xylenes t $n$ a d ethanol solution. Endogenous peroxida was anched with $1 \% \mathrm{H} 2 \mathrm{O} 2$ solution. The speciens were ynsed in PBS and sealed with $3 \%$ BSA at ro 1 cmperaturefor $1 \mathrm{~h}$. Protein expression in tissues was cected with SOX13 and PAX8 primary antibody (Abcam) and DAB labeled secondary antibodies. The staining results were analyzed by Image J software.

\section{Virus packaging and infection}

Lentiviruses containing the shRNA targeting SOX13 or PAX8 were generated following the protocol described by Addgene. The plasmids were co-transfected into the packaged cell line HEK293T. After $48 \mathrm{~h}$, the virus supernatant was collected, filtered and clarified, and concentrated by super-centrifugation. $5 \times 10^{5} \mathrm{~A}$ and MGC803 cells (30-40\% fused) placed in a $60 \mathrm{~mm}$ io were infected with a concentrated virus d $5 \mu / \mathrm{ml}$ of polybrene. $24 \mathrm{~h}$ later, cells were screned th $2 \mu \mathrm{g} / \mathrm{ml}$ of proteromycin (Sigma) for 1 wer $k$.

\section{RNA extraction and qRT-P $-\mathrm{R}$}

Total RNA was isolate a tissu o or cells using Trizol reagent (Invitrogen). The $t$ strand of cDNA was obtained using RN 1 templa, 2 with reverse transcription kits (TOYOB Q $Q$ - titative analysis of all gene transcripts was perfo, ed with the Power SYBR Green PCR Master $N \quad$ (TOY,$\omega O$ ) on the ABI 7500 series system (Applied lios $y_{3}$ ns, Foster City, CA). The internal reference gen was GAPDH, and the primers are listed in 1 . 1 .

\section{Jmatin immunoprecipitation (ChIP assay)}

ChIP assay was performed with EZ-ChIP Kits (Millipore) to verify SOX13 local on the PAX8 promoter region according to kit instructions. Immunoprecipitation was performed with SOX13 antibody (Abcam) to obtain targeted DNA fragments. Quantitative PCR analysis was performed with the Power SYBR Green PCR Master Mix on the ABI 7500 sequence detection system (Applied Biosystems, Foster City, CA).

\section{Luciferase assay}

AGS cells were transfected with pGL3 report vectors with different PAX8 promoter fragments with plasmids expressing SOX13. Renilla vector was used as a negative control. Cells were collected $36 \mathrm{~h}$ later and luciferase activity was measured with the Double Luciferase Reporter Assay System (Promega). Firefly luciferase activity were normalized to Renilla luciferase activity.

\section{Flow cytometry}

Trypsin collected cells were washed with PBS and fixed overnight at $-20{ }^{\circ} \mathrm{C}$ with $70 \%$ ethanol. After centrifugation, the fixed cells were washed with PBS and stained for $20 \mathrm{~min}$ with $100 \mu \mathrm{g} / \mathrm{ml}$ RNase A (Sigma) and $50 \mathrm{mg} /$ $\mathrm{ml}$ propidium iodide (Sigma) in $500 \mu \mathrm{l}$ PBS. Cell cycle data were acquired by FACSCalibur system (BD Biosciences). 
Table 1 Primers used for quantitative real-time PCR

\begin{tabular}{ll}
\hline Gene & Primers (5' to 3', forward/reverse) \\
\hline SOX13 & CCAGAGGGTAATGGGTCCC / TGGCTTCCATAGAGTTCCTTCC \\
PAX8 & ATCCGGCCTGGAGTGATAGG / TGGCGTTTGTAGTCCCCAATC \\
Aurora B & CAGAAGAGCTGCACATTGACG / CCTTGAGCCCTAAGAGCAGATT \\
Cyclin B1 & ACGAAGGTCTGCGCGTGTT / CCGCTGGCCATGAACTACR \\
GAPDH & GGAGCGAGATCCCTCCAAAAT / GGCTGTTTCATACT \\
PAX8 promote & GAACAGAGGGATGGCTTC/CCAGAAGTGAGAGGGATGGT \\
\hline
\end{tabular}

\section{EdU incorporation assay}

About 2000 cells of different genotypes were planted on 96-well plates and cultured at $37^{\circ} \mathrm{C}$ for $24 \mathrm{~h}$. After that, $20 \mathrm{mM}$ EdU was added and continued to be cultured for $2 \mathrm{~h}$. Cells were collected, fixed with $4 \%$ formaldehyde, stained with EdU Apollo@594 in vitro imaging kit (Ribo) according to the instructions. EdU incorporation rate was determined by leica inverted fluorescence microscopy.

\section{Colony formation}

One thousand cells of different genotypes were plated in three copies in a 6-well dish. After 14 days of training, the colonies were dyed with $0.5 \%$ crystal violet $/ 20 \%$ ethanol and counted. Results were normalized to plating efficiencies. Results are expressed as the average of three independent experimental data.

\section{Statistical analysis}

All experiments were independently epeate for 3 times, and results were expressed as nean \pm SD. CraphPad Prism software (version 5.01) w: used fo statistical analysis, and $p<0.05$ was considered ticti ally significant $(* \mathrm{p}<0.05, * p<0.01, * * 001)$. The paired $\mathrm{t}$ test was used to analyze the ger $\mathrm{e} e \mathrm{x}_{\mathrm{L}}$ - ession differences in the paired tissues, an the couble-tailed $t$-test was used to evaluate the or roups of independent repeated experim nts. distribution differences of SOX13 and $\mathrm{P} \Omega$ in tissue, were analyzed by $\mathrm{X}^{2}$ test.

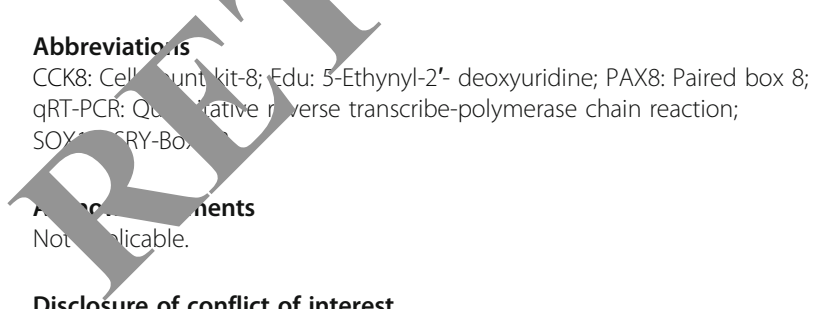

Disclosure of conflict of interest

The authors declare that they have no conflict of interest.

\section{Authors' contributions}

LYB and SXL designed and performed the experiments; NL, WYD, XYL and PG contributed reagents/materials/analysis tools; SXL wrote the paper. All authors read and approved the final manuscript.

\section{Funding}

None.

\section{Availability of data and materials}

All data generated or analysed during this stu published article or supplementary files.

Ethics approval and consent to partic

Not applicable.

\section{Consent for publication}

The publication has boproved all authors.

\section{Competing interest}

The authors declare tha v have no competing interests.

\section{Author detai s}

${ }^{1}$ Department of Oncology, Affiliated Cancer Hospital of Zhengzhou University Henal Gancer Hospital, Zhengzhou, NO. 127, Dongming Road,

District, Zhengzhou 450008, Henan, China. ²Department of Pathology,

Affilia. Cancer Hospital of Zhengzhou University Henan Cancer Hospital,

hengz ou 450008, Henan, China. ${ }^{3}$ Department of Oncology, the First ate d Hospital of Nanyang Medical College, Nanyang 473061, Henan,

Received: 23 June 2019 Accepted: 20 December 2019

Published online: 27 December 2019

\section{References}

1. Bijlsma MF, Sadanandam A, Tan P, Vermeulen L. Molecular subtypes in cancers of the gastrointestinal tract. Nat Rev Gastroenterol Hepatol. 2017; 14(6):333-42.

2. Balakrishnan M, George R, Sharma A, Graham DY. Changing trends in stomach Cancer throughout the world. Curr Gastroenterol Rep. 2017; 19(8):36.

3. Fitzmaurice C, Akinyemiju TF, Al Lami FH, Alam T, Alizadeh-Navaei R, Allen C, Alsharif U, Alvis-Guzman N, Amini E, Anderson BO, et al. Global, regional, and National Cancer Incidence, mortality, years of life lost, years lived with disability, and disability-adjusted life-years for 29 Cancer groups, 1990 to 2016: a systematic analysis for the global burden of disease study. JAMA oncol. 2018;4(11):1553-68.

4. Ding K, Tan S, Huang X, Wang X, Li X, Fan R, Zhu Y, Lobie PE, Wang W, Wu Z. GSE1 predicts poor survival outcome in stomach cancer patients by SLC7A5 enhancement of tumor growth and metastasis. J Biol Chem. 2018; 293(11):3949-64.

5. Zheng J, Rutegard M, Santoni G, Wallner B, Johansson I, Sund M, Xie SH, Lagergren J. Prediabetes and diabetes in relation to risk of stomach adenocarcinoma. Br J Cancer. 2019.

6. Kankeu Fonkoua L, Yee NS. Molecular Characterization of Stomach Carcinoma: Therapeutic Implications for Biomarkers and Targets. Biomedicines. 2018;6(1).

7. Cidon EU, Ellis SG, Inam Y, Adeleke S, Zarif S, Geldart T. Molecular targeted agents for stomach cancer: a step forward towards personalized therapy. Cancers. 2013;5(1):64-91.

8. Kim TJ, Lee H. Diabetic biomarkers and the risk of proximal or distal stomach cancer. J Gastroenterol Hepatol. 2016;31(10):1705-10.

9. Chi N, Epstein JA. Getting your Pax straight: Pax proteins in development and disease. Trends in genetics: TIG. 2002;18(1):41-7.

10. Mansouri A, Chowdhury K, Gruss P. Follicular cells of the thyroid gland require Pax8 gene function. Nat Genet. 1998;19(1):87-90. 
11. Mittag J, Winterhager E, Bauer K, Grummer R. Congenital hypothyroid female pax8-deficient mice are infertile despite thyroid hormone replacement therapy. Endocrinology. 2007;148(2):719-25.

12. Li CG, Nyman JE, Braithwaite AW, Eccles MR. PAX8 promotes tumor cell growth by transcriptionally regulating E2F1 and stabilizing RB protein. Oncogene. 2011:30(48):4824-34.

13. Laury AR, Hornick JL, Perets R, Krane JF, Corson J, Drapkin R, Hirsch MS. PAX8 reliably distinguishes ovarian serous tumors from malignant mesothelioma. Am J Surg Pathol. 2010;34(5):627-35.

14. Laury AR, Perets R, Piao H, Krane JF, Barletta JA, French C, Chirieac LR, Lis R, Loda $\mathrm{M}$, Hornick $\mathrm{J}$, et al. A comprehensive analysis of PAX8 expression in human epithelial tumors. Am J Surg Pathol. 2011;35(6):816-26.

15. Nonaka D, Chiriboga L, Soslow RA. Expression of pax8 as a useful marker in distinguishing ovarian carcinomas from mammary carcinomas. Am J Surg Pathol. 2008:32(10):1566-71.

16. Melichar HJ, Narayan K, Der SD, Hiraoka Y, Gardiol N, Jeannet G, Held W, Chambers CA, Kang J. Regulation of gammadelta versus alphabeta $T$ lymphocyte differentiation by the transcription factor SOX13. Science (New York, NY). 2007;315(5809):230-3.

17. Marfil V, Moya M, Pierreux CE, Castell JV, Lemaigre FP, Real FX, Bort R. Interaction between Hhex and SOX13 modulates Wnt/TCF activity. J Bio Chem. 2010;285(8):5726-37.

18. Kido S, Hiraoka Y, Ogawa M, Sakai Y, Yoshimura Y, Aiso S. Cloning and characterization of mouse mSox13 cDNA. Gene. 1998;208(2):201-6.

19. Roose J, Korver W, de Boer R, Kuipers J, Hurenkamp J, Clevers H. The Sox-13 gene: structure, promoter characterization, and chromosomal localization. Genomics. 1999;57(2):301-5.

20. He Z, Ruan X, Liu X, Zheng J, Liu Y, Liu L, Ma J, Shao L, Wang D, Shen S, et al. FUS/circ_002136/miR-138-5p/SOX13 feedback loop regulates angiogenesis in Glioma. J Exp Clin Cancer Res. 2019;38(1):65.

21. Comprehensive molecular characterization of stomach adenocarcinoma. Nat. 2014;513(7517):202-9.

22. Chen YL, Cheng KC, Lai SW, Tsai IJ, Lin CC, Sung FC, Lin CC, Chen PC. Diabetes and risk of subsequent stomach cancer: a population-based cohort study in Taiwan. Stomach Cancer : Official J Int Stomach Ca Assoc Japanese Stomach Cancer Assoc. 2013;16(3):389-96.

23. Liu Y, Sethi NS, Hinoue T, Schneider BG, Cherniack AD, Sanch z-Vega $F$ Seoane JA, Farshidfar F, Bowlby R, Islam M, et al. Compar a. Molecular Analysis of Gastrointestinal Adenocarcinomas. Cancer, Ce (. 20 to 4):721735.e728.

24. Duraes C, Almeida GM, Seruca R, Oliveira C, Carr iro F. Biomarkers hor stomach cancer: prognostic, predictive or targe of therapy? Virchows Archiv : Int J Pathol. 2014;464(3):367-78.

25. Posenato I, Calio A, Segala D, Sgroi S, Rolara A, Brum, , Martignoni G. Primary seminal vesicle carcinoma. The immunohistochemical expression for the diff 16 , diagnosis. Hum Pathol. 2017;69:123-8

26. Kar SP, Adler E, Tyrer J, Hz alett $\mathrm{L}$ Anton-C Yver H, Bandera EV, Beckmann MW, Berchuck A, Bogdana et al. Enrichment of putative PAX8 target genes at serous helial ovarian cancer susceptibility loci. Br J Cancer. 2017:116 24-35.

27. Koumarianou Go, Lopez G, Santisteban P. Pax8 controls thyroid follicular n 'arity throus actherin-16. J Cell Sci. 2017;130(1):219-31.

28. Hung A, Eiholzer RA, Kiyo S, Zhou J, Ward-Hartstonge K, Wiles AK, Frant C Tahl A, Royds JA, Slatter TL. Telomere profiles and tumorassociate acrop áges with different immune signatures affect prognosis 21 oblasto

Hochedlinger $\mathrm{K}$. The sox family of transcription factors: जtile regulators of stem and progenitor cell fate. Cell Stem Cell. 20) $3 ; 12(1): 15-30$.

30. Kamachi Y, Kondoh H. Sox proteins: regulators of cell fate specification and differentiation. Dev (Cambridge, England). 2013;140(20):4129-44.

31. Ivanov SV, Panaccione A, Nonaka D, Prasad ML, Boyd KL, Brown B, Guo Y, Sewell A, Yarbrough WG. Diagnostic SOX10 gene signatures in salivary adenoid cystic and breast basal-like carcinomas. Br J Cancer. 2013;109(2): $444-51$

32. Huang W, Chen Z, Shang X, Tian D, Wang D, Wu K, Fan D, Xia L. Sox12, a direct target of FoxQ1, promotes hepatocellular carcinoma metastasis through up-regulating Twist1 and FGFBP1. Hepatol (Baltimore, Md). 2015; 61(6):1920-33.
33. Duquet A, Melotti A, Mishra S, Malerba M, Seth C, Conod A, Ruiz i Altaba A. A novel genome-wide in vivo screen for metastatic suppressors in human colon cancer identifies the positive WNT-TCF pathway modulators TMED3 and SOX12. EMBO Mol Med. 2014;6(7):882-901.

\section{Publisher's Note}

Springer Nature remains neutral with regard to jurisdictional claims in published maps and institutional affiliations.

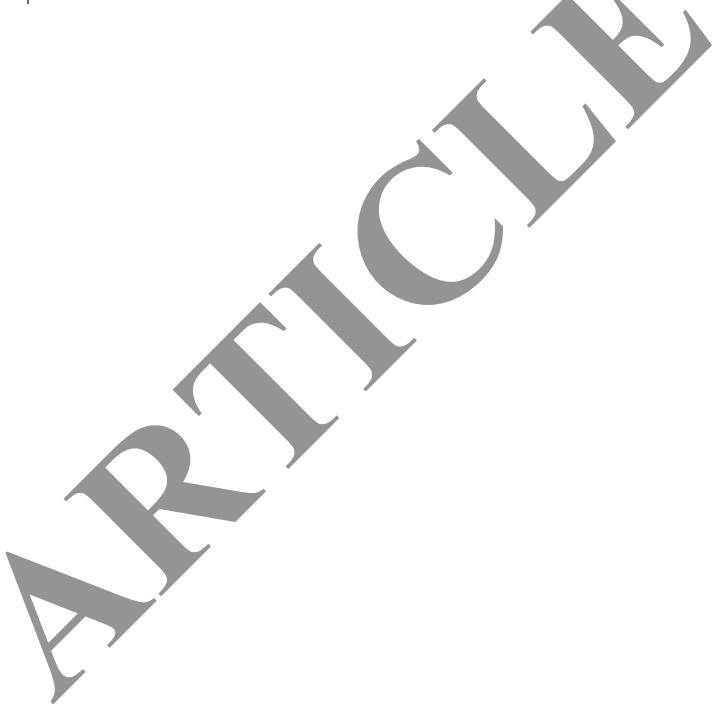

Ready to submit your research? Choose BMC and benefit from:

- fast, convenient online submission

- thorough peer review by experienced researchers in your field

- rapid publication on acceptance

- support for research data, including large and complex data types

- gold Open Access which fosters wider collaboration and increased citations

- maximum visibility for your research: over $100 \mathrm{M}$ website views per year

At BMC, research is always in progress.

Learn more biomedcentral.com/submissions 